\title{
The relationship between signal quality and physical condition: is sexual signalling honest in the three-spined stickleback?
}

\author{
ULRIKA CANDOLIN \\ Department of Biology, University of Turku \\ (Received 17 May 1999; initial acceptance 13 July 1999; \\ final acceptance 16 August 1999; MS. number: 6229)
}

\begin{abstract}
Honest sexual signalling requires that the level of advertisement reveals mate quality. In the three-spined stickleback, Gasterosteus aculeatus, females base their mate choice mainly on the intensity of the males' red breeding coloration. Different results have, however, been obtained on the relationship between red breeding coloration and physical condition. In this study, the relationship was curvilinear in a natural population, with males in good and poor condition (measured as lipid content) having larger red areas than males of intermediate condition. By manipulating food intake and thus male condition prior to breeding, I further show that poor condition can induce an increase in signalling effort. This effect was further strengthened when the predation cost of signalling was increased by exposing the males to predators. This suggests that the reason for the high signalling effort of males in poor condition is their low probability of future reproduction and thus lower cost of signalling in terms of loss of future reproductive opportunities. Males in poor condition signal as a terminal effort and take larger risks and invest more in current reproduction than males in good condition. Finally, I discuss whether an effect of decreasing residual reproductive value on signalling effort could result in the breakdown of the honesty of the signal.
\end{abstract}

(ㄷ) 1999 The Association for the Study of Animal Behaviour

In many species, females base their mate choice on the degree of exaggeration of the males' secondary sexual characters (reviewed by Andersson 1994). Two main mechanisms have been proposed to explain the evolution of such mating preferences: direct selection on preference genes and indirect genetic effects (reviewed by Kirkpatrick \& Ryan 1991; Andersson 1994). According to the direct selection mechanism, preferences evolve because of direct fitness benefits for females. The indirect mechanism, on the other hand, claims that preferences evolve because of genetic benefits to the offspring, that is, the inheritance of genes for attractiveness (Fisher 1915, 1930) or viability (Zahavi 1975, 1977).

Whether the benefits are direct or indirect, a prerequisite for female choice is that the level of exaggeration indicates the benefits in question honestly. According to Zahavi's handicap principle, signals will be honest only if constrained by the differential costs of producing and maintaining them, that is, the exaggeration of the trait has to be more costly for males of low than high quality (Zahavi 1975, 1977; Grafen 1990a, b), unless the signals are in some sense uncheatable. However, theoretical models indicate that signals need only be Correspondence and present address: U. Candolin, School of Biological Sciences, University of East Anglia, Norwich NR4 7TJ, U.K. (email: u.candolin@uea.ac.uk).

0003-3472/99/121261+07\$30.00/0 honest 'on average' for a signalling system to be stable (Johnstone \& Grafen 1993; Kokko 1997). Dishonest signalling could occur in a stable system provided that the frequency of 'cheaters' is sufficiently low. Signallers could be dishonest if they differ in their signalling strategies because of variation in the costs or benefits of signalling or in their relatedness to the receiver (Johnstone \& Grafen 1993) or if the expression of the trait is subject to a life history trade-off between present and future signalling effort (Kokko 1997).

Several empirical studies have investigated the costs and honesty of signals. In the majority of published studies, a positive correlation between signal expression and some putative measure of quality has been found, and in some of these there is evidence of fecundity benefits or higher survival of offspring (reviewed by Johnstone 1995). The honest indicator process is thus supported by empirical evidence.

In the three-spined stickleback, Gasterosteus aculeatus, females base their mate choice mainly on the intensity of the males' red breeding coloration (reviewed by Rowland 1994), which is due to carotenoids that the male acquires through feeding (Wedekind et al. 1998). The coloration may work as a handicap as it is energetically costly (Frischknecht 1993), increases the risk of predation (Moodie 1972; Whoriskey \& FitzGerald 1985) and 
probably reduces immunocompetence (Milinski \& Bakker 1990; Lozano 1994; Skarstein \& Folstad 1996; Wedekind et al. 1998). It could indicate both direct benefits, such as fertilization success and parental ability, and indirect genetic benefits, since coloration has a genetic component (Bakker 1993). The male's parental ability, in particular, should be an important measure of male quality as the male alone cares for the developing eggs and offspring for about 2 weeks by fanning and guarding them against predators. Here, male condition should be of importance since male reproductive activities are energetically expensive (Chellappa et al. 1989; FitzGerald et al. 1989) and males in very poor condition may die during the parental phase and thus fail to rear the offspring to independence, or they may eat their own eggs to improve their condition (Whoriskey \& FitzGerald 1994). Condition could also indicate general viability and underlying genetic quality, and thus indicate indirect benefits.

Different results have, however, been obtained on the relationship between the intensity of red coloration and physical condition. Some studies have found a positive relationship (Milinski \& Bakker 1990; Frischknecht 1993), whereas others have not (Hosking 1996; Baube 1997), and one correlative study has even found the relationship to differ between subpopulations (Bakker \& Mundwiler 1994). These studies have based their results on the condition factor (an index of wet weight in relation to body length), which is an indirect measure and more unreliable than direct measures (Chellappa et al. 1995).

I investigated the relationship between red coloration and physical condition using lipid content, a short- to medium-term energy store, as a direct measure of physical condition. I determined the relationship both for a natural population and for males whose condition was manipulated prior to breeding. The manipulative study was undertaken to eliminate other factors, such as earlier breeding cycles, which may confound the results of the correlative study. Sticklebacks in this population have a single breeding season during which they breed repeatedly and lipid content could thus depend on the number of earlier cycles.

I also investigated whether a life history trade-off between present and future signalling effort could affect signalling and confound a positive correlation between signal quality and male condition. The condition of the male deteriorates during breeding, and males that die at the end of the breeding season may have exhausted their energy reserves (Chellappa et al. 1989). Male condition should therefore influence residual reproductive value that is, the probability of future reproduction, which in turn could determine the investment in current reproduction. I investigated this by exposing the condition-manipulated males to predators. Stickleback males usually show less red colour in the presence of predators (Candolin 1998). However, if males in poor condition have fewer future reproductive opportunities than males in good condition, they may invest relatively more in present reproduction and consequently take larger predation risks and reduce their red colour less.

\section{METHODS}

\section{The Natural Population}

I recorded physical condition and breeding coloration of 35 courting males with nest depths of $30-60 \mathrm{~cm}$ in a shallow bay (maximum depth $1.5 \mathrm{~m}$ ) in the archipelago near Tvärminne Zoological Station in southern Finland $\left(60^{\circ} \mathrm{N}, 23^{\circ} \mathrm{E}\right)$. The recordings were done during 2 weeks at the beginning of June 1997. In this year males bred from mid-May to late July.

To record the breeding coloration, I hand-netted males and photographed them under standardized conditions. The method corresponds to that of Frischknecht (1993), but I used digital images to eliminate any confounding effects of film development. I put the male into a small glass box $(6 \times 3 \times 6 \mathrm{~cm})$ containing water and a black sponge that fixed him in position and served as a nonreflecting background. The box was then placed in a fixed position in a large dark box containing a digital camera (Kodak DC 50) and the left side of the male was photographed. The lateral view of the males is exposed to females during courtship. The difference in red area between the left and the right sides is usually less than $10 \%$ (unpublished data) and so I photographed only the left side of the males to minimize the time that they had to be enclosed in the small glass box. The only light source was a lateral flash (guide number 10.4, ISO 84). To make sure that the conditions were constant, I attached three plastic strings, one red, one blue and one green, to the front side of the glass box to serve as colour references in the analyses. The netting and photography procedure took less than $1 \mathrm{~min}$ and the males did not have time to fade as a result of handling stress. The males were in the small glass box for a maximum of $10 \mathrm{~s}$. I used a tristimulus system constructed to fit the human eye, as colour vision of sticklebacks does not differ greatly from that of humans (reviewed by Frischknecht 1993; McKinnon 1995). I humanely killed the males immediately after photography by putting them into a bucket with anaesthetic (MS-222). They were then frozen for storage until lipid measurement.

I determined the extent and quality of the red nuptial coloration from the digital images using image analysis software (MCID-M4, Imaging Research Inc., Proc University, St Catherines, Ontario, Canada). I selected areas that ranged in colour from yellow to red to purple (hue: 1-50 and 340-359; saturation (chroma): 0-0.631; intensity (brightness): 0.157-0.663), and recorded their size and mean colour hue, saturation and intensity. Since females could base their mate choice on either the absolute or the relative size of the red areas, I used both measures in the analyses. I calculated the standardized measurements by partialling out the size of the fish through the use of the residuals from a linear regression of the size of the red area on the total area of the photographed males.

I determined the lipid content of the males by the Soxhlet method, first drying them for $24 \mathrm{~h}$ at $60^{\circ} \mathrm{C}$, and then dissolving the fat in petroleum ether until the fish attained a constant dry weight (Reznik \& Braun 1987). Three lipid extractions, each lasting $5 \mathrm{~h}$, were required. 
Lipid content was estimated as the percentage of dry weight lost.

\section{Condition-manipulated Males}

I collected three-spined sticklebacks by fry traps from the same population as mentioned above before the breeding season (early May). The fish were housed in holding aquaria at $16^{\circ} \mathrm{C}$ under a $18: 6 \mathrm{~h}$ light:dark cycle at a density of 10 fish per 125-litre aquarium. They were fed once a day with commercial flake food and frozen chironomid larvae. The predators, perch, Perca fluviatilis, were collected with a seine. Two perch at a time were maintained in a large holding aquaria $(150 \times 60 \mathrm{~cm}$ and $40 \mathrm{~cm}$ high) for 4-6 days and 10 perch $(24-30 \mathrm{~cm}$ standard length) were used in the experiments. The perch were maintained at the same lighting and temperature conditions as the sticklebacks. They were not fed for the 4-6 days and were all healthy when released at the site of capture. Perch is a natural predator on sticklebacks in the study area (personal observation).

After 1 week of maintenance, I separated stickleback males from females on the basis of hints of nuptial coloration and randomly assigned the males to two different feeding treatments. For 3 weeks, one group of males was food deprived, whereas the other was fed in excess twice a day with carotenoid-free fish food (Rehuraisio Ltd, Raiso, Finland). I used carotenoid-free food to eliminate the possibility that differences in the supply of carotenoids would cause differences in nuptial coloration between the two treatment groups. Breeding behaviour was discouraged by the lack of suitable nesting materials. Females were maintained in separate holding aquaria and fed ad libitum with chironomid larvae and commercial flake food to ensure a constant supply of gravid females. They were released at the site of capture after the experiments.

After 3 weeks of food manipulation, I allowed 22 food-deprived $(\bar{X} \pm \mathrm{SE}=53.1 \pm 0.5 \mathrm{~mm}$ standard length) and 22 fed males $(53.1 \pm 0.6 \mathrm{~mm}$ standard length) to nest individually in aquaria $(35 \times 45 \mathrm{~cm}$ and $30 \mathrm{~cm}$ high). The aquaria were placed in rows, with food-deprived and fed males in alternating order. Behind each row of four aquaria was a large aquarium $(150 \times 60 \mathrm{~cm}$ and $40 \mathrm{~cm}$ high), which was later used for predator presentation. The experiment was thus blocked by the large aquaria. White opaque sheets prevented the males seeing each other. White curtains with small viewing holes reduced external disturbances. Each male's aquarium contained a nesting dish (14 cm in diameter) in one of the front corners, filled with $1 \mathrm{~cm}$ of sand, an artificial plant, and some Cladophora as nesting material.

To stimulate nest building, I exposed each male to a gravid female for 2 min twice a day for 2 consecutive days. The female was enclosed in a Plexiglas cylinder $(10 \mathrm{~cm}$ in diameter) which was placed in the back corner of the male's aquarium. Only females that were ready to spawn were used, judged from the distension of their belly, the opening of their cloacae, and the performance of a head-up posture. On the third day, males were exposed for 10 min to a gravid female ready to spawn.
I recorded male courtship behaviour, that is, the frequency of leads to the nest and the total time spent courting. In this population, the frequency of leads (whereby the male attempts to lead the female to the nest to spawn), and not zigzag movements, reflects male courtship intensity and attractiveness to females (Candolin 1997). I recorded the nuptial coloration after courtship recording using the same method as described above.

On the next day I investigated the effect of an increased cost of signalling on signalling effort. I placed two perch into the large, empty aquarium behind each block of four stickleback tanks 30 min before I exposed the males to a gravid female for $10 \mathrm{~min}$. An opaque sheet on the back of the female's cylinder prevented the female from viewing the predators. I recorded courtship behaviour, nuptial coloration and lipid content as described above. The stomachs of both food-deprived and fed males were empty, which suggests that the males did not feed on the Cladophora to any great extent to increase their carotenoid content.

\section{Statistics}

I used nonparametric tests when the assumption of normality was violated. Values reported are means $\pm \mathrm{SE}$.

\section{Ethical Note}

The food-deprived males were all alive and healthy at the end of the 3 weeks. They did not differ in behaviour from fed males and it was not possible to tell by observation which males during the 3 weeks of food deprivation were in poor condition. The lipid contents of the food-deprived males were within the range found in nature (compare Figs 1 and 2). Sticklebacks do not usually feed during the 2-3-week parental phase and thus sustain food deprivation well (Wootton 1976). They are able to recover from 3 weeks of food deprivation (personal observation). Males showed no signs of distress during the photography procedures or the 4 days of experimentation. They resumed normal behaviour within $1 \mathrm{~min}$ of the photography procedure. Males spent more time hiding during the predator exposure, and they performed predator inspection behaviour, but they resumed normal behaviour when the predators were removed. Sticklebacks are stress tolerant and adapt readily to the laboratory. Live predators had to be used, as sticklebacks habituate to model predators. My research was approved by the Animal Care Committee of the University of Helsinki.

\section{RESULTS}

\section{The Natural Population}

The relationship between lipid content and the standardized area of red colour was best described by a curvilinear regression model (Fig. 1). No linear relationship was found (linear regression: $b=-0.004, r^{2}=0.03$, 


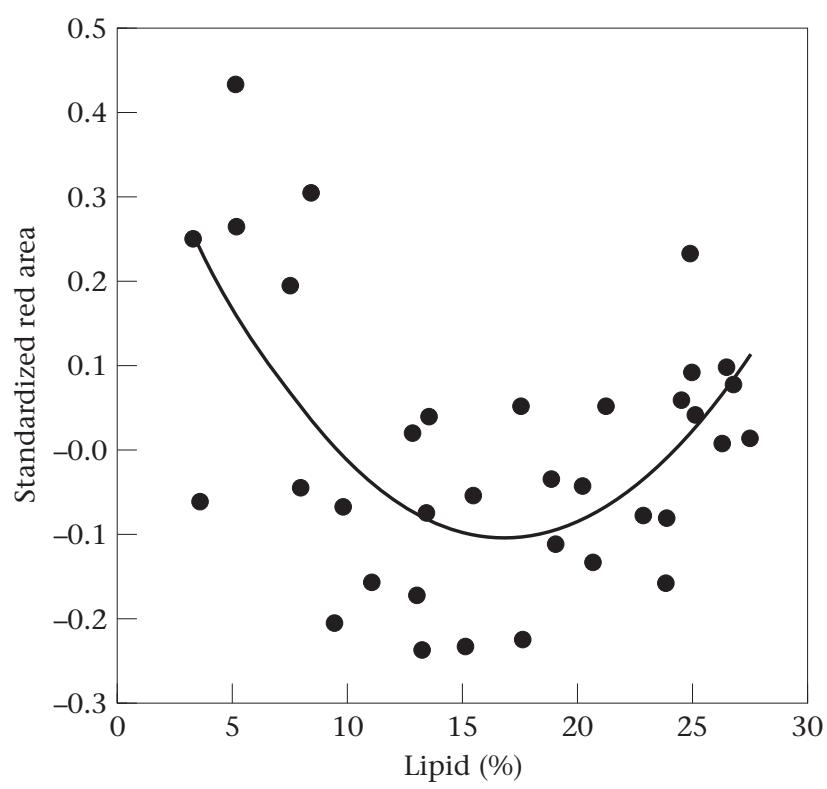

Figure 1. The relationship between lipid content as a percentage of dry weight and standardized red area. $Y=0.44-0.06$ ( $S E=0.01$, $P<0.001) X+0.002(\mathrm{SE}=0.000, P<0.001) X^{2}, r^{2}=0.36$. Standardized red area was calculated by partialling out the size of the fish through the use of residuals from a linear regression of the size of the red area on the total area of the photographed males.

$\left.F_{1,33}=1.10, P>0.3\right)$. Males in good and poor condition thus had larger red areas than males of intermediate condition. The same results were obtained with absolute red areas (quadratic regression: $r^{2}=0.35$; linear regression: $\left.r^{2}=0.03\right)$. No relationship, either linear or curvilinear, was found between lipid content and mean hue, saturation, or intensity of the red areas (linear and quadratic regression of the colour traits on lipid content, all Ps $>0.1)$.

\section{Condition-manipulated Males}

Food-deprived males had less lipid than fed males ( $8.4 \pm 0.8$ versus $19.0 \pm 1.4 \%$; $t$ test for unequal variances: $\left.t_{34.9}=6.55, P<0.001\right)$. Since there was no effect of blocks $(P>0.4)$, and the statistical analysis with and without block design yielded the same results, statistical values are reported for analyses without blocks.

Food-deprived males had larger standardized red areas than fed males $\left(t_{42}=2.04, P<0.05\right)$, and the difference increased when predators were present (Fig. 2, Table 1). This was due to fed males showing a larger percentage reduction in the absolute size of the red areas than food-deprived males when exposed to predators $\left(43.1 \pm 7.1\right.$ versus $\left.8.2 \pm 4.6 \% ; t_{42}=4.12, P<0.0001\right)$. The same results, but even more significant, were obtained with absolute red areas (red area of food-deprived and fed males: without predators: $1.12 \pm 0.08$ and $0.80 \pm$ $0.09 \mathrm{~cm}^{2}$, respectively; with predators: $0.99 \pm 0.06$ and $0.45 \pm 0.08 \mathrm{~cm}^{2}$, respectively; repeated measures ANOVA: feeding treatment: $F_{1,42}=17.8, \quad P<0.001$; predator $\times$ feeding treatment: $\left.F_{1,42}=8.25, P<0.01\right)$. Food-deprived males also had brighter red areas than fed males, as they
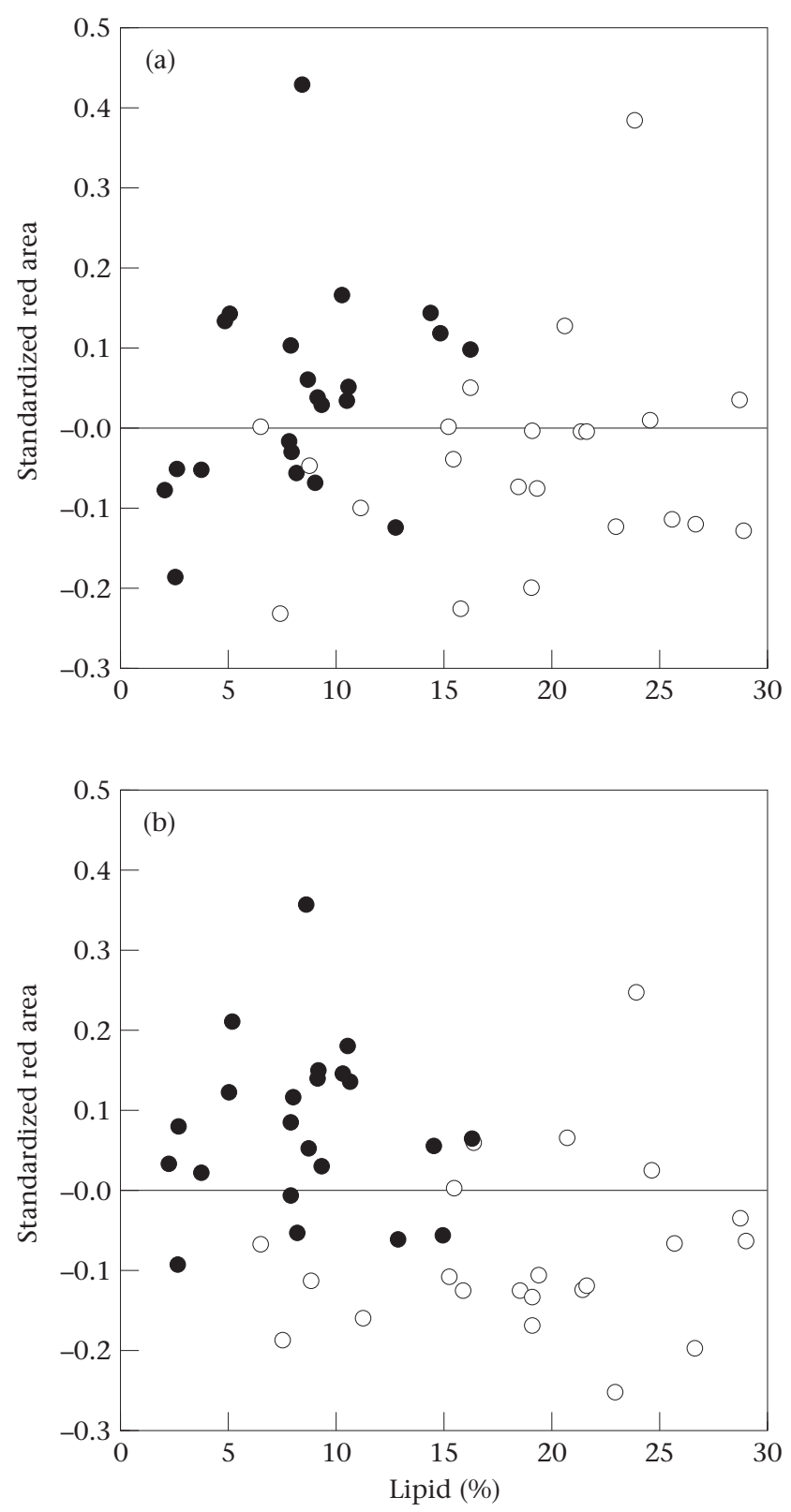

Figure 2. Lipid content as a percentage of dry weight and standardized red area of food-deprived $(\bullet)$ and fed males ( $(0)$ in the (a) absence and (b) presence of predators.

had lower intensity values but the same hue and saturation values as fed males (Table 1, a low value of intensity indicates brightly coloured fish as red colours reduce the amount of light reflected compared with the otherwise silvery skin of sticklebacks).

Feeding treatment did not influence courtship activity in the absence of predators (Table 2). Fed males, however, showed a larger predator-induced reduction in courtship activity than food-deprived males (Table 2).

\section{DISCUSSION}

Red coloration showed a curvilinear relationship to lipid content. It was thus not an honest indicator of condition 
Table 1. Size (standardized), hue, saturation and intensity of the red areas of food-deprived and fed males in the absence and presence of predators

\begin{tabular}{|c|c|c|c|c|c|c|c|}
\hline \multirow[b]{2}{*}{ Colour } & \multirow[b]{2}{*}{ Treatment } & \multicolumn{2}{|c|}{ Predators } & \multicolumn{2}{|c|}{ Treatment } & \multicolumn{2}{|c|}{ Repeat } \\
\hline & & Absent & Present & $F_{1.42}$ & $P$ & $F_{1.42}$ & $P$ \\
\hline Size & $\begin{array}{c}\text { Food deprived } \\
\text { Fed }\end{array}$ & $\begin{array}{r}0.04 \pm 0.03 \\
-0.04 \pm 0.03\end{array}$ & $\begin{array}{r}0.08 \pm 0.02 \\
-0.08 \pm 0.02\end{array}$ & 12.24 & $<0.001$ & 9.29 & $<0.01$ \\
\hline Hue & $\begin{array}{l}\text { Food deprived } \\
\text { Fed }\end{array}$ & $\begin{array}{l}33.46 \pm 2.57 \\
29.02 \pm 2.49\end{array}$ & $\begin{array}{l}33.79 \pm 2.62 \\
28.46 \pm 2.12\end{array}$ & 2.58 & NS & 0.01 & NS \\
\hline Saturation & $\begin{array}{l}\text { Food deprived } \\
\text { Fed }\end{array}$ & $\begin{array}{l}0.23 \pm 0.01 \\
0.22 \pm 0.01\end{array}$ & $\begin{array}{l}0.23 \pm 0.01 \\
0.23 \pm 0.01\end{array}$ & 0.01 & NS & 0.17 & NS \\
\hline Intensity & $\begin{array}{l}\text { Food deprived } \\
\text { Fed }\end{array}$ & $\begin{array}{l}0.48 \pm 0.01 \\
0.50 \pm 0.01\end{array}$ & $\begin{array}{l}0.51 \pm 0.01 \\
0.54 \pm 0.01\end{array}$ & 5.09 & $<0.05$ & 16.43 & $<0.001$ \\
\hline
\end{tabular}

Values are $\bar{X} \pm S E$. Repeated measures ANOVA with male feeding history as treatment and predator presence as repeated factor was used for analyses.

Table 2. Courtship activity in the absence of predators and the percentage reduction in activity when exposed to predators for the 22 food-deprived and 22 fed males

\begin{tabular}{|c|c|c|c|c|c|c|}
\hline & \multicolumn{2}{|c|}{ No predators } & & \multicolumn{2}{|c|}{$\begin{array}{l}\text { Reduction when } \\
\text { predators added (\%) }\end{array}$} & \\
\hline & Fed & Food deprived & & Fed & Food deprived & \\
\hline $\begin{array}{l}\text { Leads } / 10 \text { min } \\
\text { Time courting (s) }\end{array}$ & $\begin{array}{c}74.2 \pm 6.3 \\
596 \pm 3\end{array}$ & $\begin{array}{l}60.4 \pm 7.6 \\
592 \pm 5\end{array}$ & $\begin{array}{c}t_{42}=1.40, \mathrm{NS} \\
U=230, \mathrm{NS}\end{array}$ & $\begin{array}{l}97.1 \pm 1.7 \\
86.1 \pm 6.3\end{array}$ & $\begin{array}{l}54.8 \pm 10.9 \\
36.7 \pm 10.2\end{array}$ & $\begin{array}{l}U=83, P<0.001 \\
U=80, P<0.001\end{array}$ \\
\hline
\end{tabular}

Values are $\bar{X} \pm$ SE. Two-sample $t$ test and Mann-Whitney $U$ test were used for analyses.

measured as lipid content. This means that females are not able to discriminate between males in good and poor condition by basing their mate choice only on the extent and quality of the red areas. Since males in very poor condition may not survive the parental phase, a female that bases her mate choice only on the red coloration may mate with a poor-quality male and gain no reproductive success.

However, signals need only be honest on average for a signalling system to be stable (Johnstone \& Grafen 1993; Kokko 1997). Some cheaters can thus occur if their frequency is sufficiently low. Moreover, the relationship between condition and signal quality need not always be positive, although this has been reported for several species (e.g. Clutton-Brock 1982; Andersson 1989, 1992; Holmberg et al. 1989; Green 1991; Hill 1992; Mappes et al. 1996). According to the theory of conditiondependent signalling, viable males in good condition should be better able to pay the cost of the signal than males in poor condition and thus show larger signal expression. However, owing to the confounding effect of signal cost, there may not be a positive correlation between male condition and signal expression. Highquality males are expected to be the most viable males in the best condition, but since they bear the most costly ornaments, the two traits may cancel out (Nur \& Hasson 1984; Zeh \& Zeh 1988; Grafen 1990b; Price et al. 1993; Johnstone 1995). The males in the natural population in poor condition and with large red areas could have been of high genetic quality, but suffering from a deterioration in condition because they had completed an earlier breeding cycle and/or were maintaining a high signalling effort. This possibility is supported by the fact that the five males in poor condition and with large red areas seem to form an outgroup. The breeding season had started 2-3 weeks before I caught the males and some males may already have completed one breeding cycle. The system may thus have provided a stronger correlation between male condition and signal quality at the start of the breeding season.

My manipulation of male condition before the start of the breeding season shows, however, that feeding history and the condition of a male can influence signalling effort. Males that had been deprived of food for 3 weeks developed larger and brighter red areas than fed males. This difference in signalling effort between food-deprived and fed males was further increased when the predation cost of signalling was increased. This is expected if impaired condition reduces the probability of survival and future reproduction more strongly when predation risk is high. Signalling costs may then be lower for poorthan high-quality males since their residual reproductive value is lower, and they are consequently expected to increase their signalling effort as a terminal investment when their condition decreases. The dishonesty of signalling in relation to male condition would then be due to the system not fulfilling the assumption of the handicap model of higher marginal costs of signalling for males of low quality than for males of high quality (Grafen 1990a, b). This possibility is supported by a recent model that indicates that dishonesty may occur in a system if survival is virtually impossible below a minimum body 
condition, or if a certain investment is required to retain the physiological state required for reproduction (see Figure 1b in Kokko 1998). Under these circumstances, males of intermediate condition may allocate more to self-maintenance than to signalling compared with males in good and poor condition. The results are further in line with the findings of an earlier study of increased risk taking and investment in red coloration in the presence of predators when future reproductive opportunities decrease (Candolin 1998).

How does this effect of residual reproductive value on signalling effort then affect the honesty of the signal? For signalling to be honest, the signals must at least partly reflect direct benefits. Males in poor condition should be better fathers than males of intermediate condition. This could be achieved if a male in poor condition invested more resources in parental care than a male of intermediate condition. However, it is unlikely that a three-spined stickleback male in very poor condition could defend and care for the offspring long enough to rear them to independence. On the other hand, a stickleback male in poor condition could eat some eggs to increase his probability of survival so that at least some of his offspring reach independence (Rohwer 1978; Sargent 1992). Nevertheless, the male would still be a less successful father than a male in good condition, if such a male is able to rear all offspring to independence.

Hence, the effect of residual reproductive value on signalling effort may decrease the honesty of the signal. The signalling system could, however, be honest on average if the frequency of cheaters is sufficiently low, that is, if only males in very poor condition fail to rear the offspring to independence. Another possibility is that females are able to uncover cheaters by basing their mate choice on multiple traits (Møller \& Pomiankowski 1993). An increasing number of studies on a wide variety of species show that females do this (see for example Zuk et al. 1990; Houde 1997; Møller et al. 1998). Stickleback females could, for instance, use the blue eyes, small deviations in courtship behaviour, or the overall body shape of the male when determining male condition and thus uncover cheaters.

To conclude, this study shows that the relationship between red coloration in male sticklebacks and condition is curvilinear, and that males in poor condition increase their signal quality, probably because of an effect of residual reproductive value on signalling effort. More studies, however, are needed to determine whether an effect of residual reproductive value on signalling effort reduces the reliability of the signalling system. This depends on to what extent male condition predicts parenting ability and whether the frequency of cheaters is sufficiently low to maintain a stable system, or if females can uncover cheaters by basing their mate choice on multiple traits.

\section{Acknowledgments}

I thank Anders Berglund, Veijo Jormalainen, Kai Lindström and Anders Pape Møller for comments on the manuscript. Thanks are also due to Rudi Voigt for field assistance and Rolf Sara for help with image analysis. This study was supported by Ella and Georg Ehrnrooth Foundation, the Section of Ecology at University of Turku, and the Academy of Finland.

\section{References}

Andersson, M. 1994. Sexual Selection. Princeton, New Jersey: Princeton University Press.

Andersson, S. 1989. Sexual selection and cues for female choice in leks of Jackson's widowbird, Euplectes jacksoni. Behavioral Ecology and Sociobiology, 25, 403-410.

Andersson, S. 1992. Female preference for long tails in lekking Jackson's widowbirds: experimental evidence. Animal Behaviour, 43, 379-388.

Bakker, T. C. M. 1993. Positive genetic correlation between female preference and preferred male ornament in sticklebacks. Nature, 363, 255-257.

Bakker, T. C. M. \& Mundwiler, B. 1994. Female mate choice and male red coloration in a natural three-spined stickleback (Gasterosteus aculeatus) population. Behavioral Ecology, 5, 74-80.

Baube, C. L. 1997. Manipulations of signalling environment affect male competitive success in three-spined sticklebacks. Animal Behaviour, 53, 819-833.

Candolin, U. 1997. Predation risk affects courtship and attractiveness of competing threespine stickleback males. Behavioral Ecology and Sociobiology, 41, 81-87.

Candolin, U. 1998. Reproduction under predation risk and the trade-off between current and future reproduction in the threespine stickleback. Proceedings of the Royal Society of London, Series $B, 265,1171-1175$.

Chellappa, S., Huntingford, F. A., Strang, R. H. C. \& Thomson, R. Y. 1989. Annual variation in energy reserves in male threespined stickleback, Gasterosteus aculeatus L. (Pisces, Gasterosteidae). Journal of Fish Biology, 35, 275-286.

Chellappa, S., Huntingford, F. A., Strang, R. H. C. \& Thomson, R. Y. 1995. Condition factor and hepatosomatic index as estimates of energy status in male three-spined stickleback. Journal of Fish Biology, 47, 775-787.

Clutton-Brock, T. H. 1982. The functions of antlers. Behaviour, 70, 108-125.

Fisher, R. A. 1915. The evolution of sexual preferences. Eugenics Review, 7, 184-192.

Fisher, R. A. 1930. The Genetical Theory of Natural Selection. Oxford: Clarendon Press.

FitzGerald, G. J., Guderley, H. \& Picard, P. 1989. Hidden reproductive costs in the three-spined stickleback (Gasterosteus aculeatus). Experimental Biology, 48, 295-300.

Frischknecht, M. 1993. The breeding coloration of male threespined sticklebacks (Gasterosteus aculeatus) as an indicator of energy investment in vigour. Evolutionary Ecology, 7, 439-450.

Grafen, A. 1990a. Biological signals as handicaps. Journal of Theoretical Biology, 144, 517-546.

Grafen, A. 1990b. Sexual selection unhandicapped by the Fisher process. Journal of Theoretical Biology, 144, 473-516.

Green, A. J. 1991. Large male crests, an honest indicator of condition, are preferred by female smooth newts, Triturus vulgaris (Salamandridae) at the spermatophore transfer stage. Animal Behaviour, 41, 367-369.

Hill, G. E. 1992. Proximate basis of variation in carotenoid pigmentation in male house finches. Auk, 109, 1-12.

Holmberg, K., Edsman, L. \& Klint, T. 1989. Female mate preferences and male attributes in mallard ducks (Anas platyrhynchos). Animal Behaviour, 38, 1-7. 
Hosking, M. G. 1996. The relationships among foraging success, sexual selection and life history in the threespine stickleback (Gasterosteus aculeatus). Ph.D. thesis, Indiana University.

Houde, A. E. 1997. Sex, Color and Mate Choice in Guppies. Princeton, New Jersey: Princeton University Press.

Johnstone, R. A. 1995. Sexual selection, honest advertisement and the handicap principle: reviewing the evidence. Biological Review, 70, 1-65.

Johnstone, R. A. \& Grafen, A. 1993. Dishonesty and the handicap principle. Animal Behaviour, 46, 759-764.

Kirkpatrick, M. \& Ryan, M. J. 1991. The evolution of mating preferences and the paradox of the lek. Nature, 350, 3338.

Kokko, H. 1997. Evolutionary stable strategies of age-dependent sexual advertisement. Behavioral Ecology and Sociobiology, 41, 99-107.

Kokko, H. 1998. Should advertising parental care be honest? Proceedings of the Royal Society of London, Series B, 265, 1871-1878.

Lozano, G. A. 1994. Carotenoids, parasites, and sexual selection. Oikos, 70, 309-311.

McKinnon, J. S. 1995. Video mate preferences of female three-spined sticklebacks from populations with divergent male coloration. Animal Behaviour, 50, 1645-1655.

Mappes, J., Alatalo, R. V., Kotiaho, J. \& Parri, S. 1996. Viability costs of condition-dependent sexual male display in a drumming wolf spider. Proceedings of the Royal Society of London, Series B, 263, 785-789.

Milinski, M. \& Bakker, T. C. M. 1990. Female sticklebacks use male coloration in mate choice and hence avoid parasitized males. Nature, 344, 330-333.

Møller, A. P. \& Pomiankowski, A. 1993. Why have birds got multiple sexual ornaments? Behavioral Ecology and Sociobiology, 32, 167-176

Møller, A. P., Saino, N., Taramino, G., Galeotti, P. \& Ferrario, S. 1998. Paternity and multiple signaling: effects of a secondary sexual character and song on paternity in the barn swallow. American Naturalist, 151, 236-242.

Moodie, G. E. E. 1972. Predation, natural selection and adaptation in an unusual threespine stickleback. Heredity, 28, 155167.

Nur, N. \& Hasson, O. 1984. Phenotypic plasticity and the handicap principle. Journal of Theoretical Biology, 110, 275-297.
Price, T., Schluter, D. \& Heckman, N. E. 1993. Sexual selection when the female directly benefits. Biological Journal of the Linnean Society, 48, 187-211.

Reznik, D. \& Braun, B. 1987. Fat cycling in the mosquitofish (Gambusia affinis): fat storage as a reproductive adaptation. Oecologia, 73, 401-413.

Rohwer, S. 1978. Parent cannibalism of offspring and egg raiding as a courtship strategy. American Naturalist, 112, 429-440.

Rowland, W. J. 1994. Proximate determinants of stickleback behaviour: an evolutionary perspective. In: The Evolutionary Biology of the Threespine Stickleback (Ed. by M. A. Bell \& S. A. Foster), pp. 297-344. Oxford: Oxford University Press.

Sargent, R. C. 1992. Ecology of filial cannibalism in fish: theoretical perspectives. In: Cannibalism: Ecology and Evolution Among Diverse Taxa (Ed. by M. A. Elger \& B. J. Crespi), pp. 38-62. Oxford: Oxford University Press.

Skarstein, F. \& Folstad, I. 1996. Sexual dichromatism and the immunocompetence handicap: an observational approach using Arctic charr. Oikos, 76, 359-367.

Wedekind, C., Meyer, P., Frischknecht, M., Niggli, U. A. \& Pfander, H. 1998. Different carotenoids and potential information content of red coloration of male three-spined stickleback. Journa of Chemical Ecology, 24, 787-801.

Whoriskey, F. G. \& FitzGerald, G. J. 1985. The effects of bird predation on an estuarine stickleback (Pisces: Gasterosteidae) community. Canadian Journal of Zoology, 63, 301-307.

Whoriskey, F. G. \& FitzGerald, G. J. 1994. Ecology of the threespine stickleback on the breeding grounds. In: The Evolutionary Biology of the Threespine Stickleback (Ed. by M. A. Bell \& S. A. Foster), pp. 189-206. Oxford: Oxford University Press.

Wootton, R. J. 1976. The Biology of the Sticklebacks. London: Academic Press.

Zahavi, A. 1975. Mate selection: a selection for a handicap. Journal of Theoretical Biology, 53, 205-214.

Zahavi, A. 1977. The cost of honesty (further remarks on the handicap principle). Journal of Theoretical Biology, 67, 603-605.

Zeh, D. W. \& Zeh, J. A. 1988. Condition-dependent sexual ornaments and field tests of sexual selection theory. American Naturalist, 132, 454-459.

Zuk, M., Thornhill, R., Ligon, J. D., Johnson, K., Austad, S., Ligon, S. H., Thornhill, N. W. \& Costin, C. 1990. The role of male ornaments and courtship behavior in female mate choice of red jungle fowl. American Naturalist, 136, 459-473. 